Article

\title{
Structural Identification of the Electrostatic Hot Spots for Severe Acute Respiratory Syndrome Coronavirus Spike Protein to Be Complexed with Its Receptor ACE2 and Its Neutralizing Antibodies
}

\author{
Wei Li(1)* \\ 1 Institute of Special Environment Medicine, Nantong University, No. 9, Seyuan Road, Nantong City, Jiangsu \\ Province, P. R. China \\ * Correspondence: wli148@aucklanduni.ac.nz
}

Received: date; Accepted: date; Published: date

\begin{abstract}
The spike protein of SARS coronavirus (SARS-CoV) attaches the virus to its cellular receptor, angiotensin-converting enzyme 2 (ACE2), which is mediated by the receptor binding domain (RBD) of the spike protein. Recently, an analysis based on decade-long structural studies of SARS was reported to illustrate with atomic-level details receptor recognition by the novel coronavirus from Wuhan, i.e., 2019-nCoV. Here, this article reports a comprehensive set of structural electrostatic analysis of all SARS-CoV spike protein RBD-related structures as of February 13, 2020, aiming at identifying the electrostatic hot spots for SARS-CoV spike protein to be complexed with ACE2 and its neutralizing antibodies. First, this article identified a structural action mechanism of the F26G19 antibody (of SARS-CoV spike protein), where its Asp56 residue binds to the Arg426 of the SARS-CoV spike protein RBD against the formation of the interfacial Arg426-Glu329 salt bridges between ACE2 and the SARS-CoV spike protein RBD. Second, a hypothesis is reported that a pair of electrostatic clips exist at the interface between ACE2 and the SARS-CoV spike protein RBD, including both Arg426-Glu329 and His445-Glu23-Lys447 salt bridges. Last, this article reports a structurally identified interfacial Glu35-Arg479 salt bridge which helps stabilize the complex structure of ACE2 and the SARS-CoV spike protein RBD. Overall, the structurally identified electrostatic hot spots reported here may be useful for the design of SARS-CoV-neutralizing antibodies in future.
\end{abstract}

Keywords: SARS-CoV; Spike protein; Electrostatic hot spots; Angiotensin-converting enzyme 2 (ACE2); Neutralizing antibody

\section{Introduction}

The world is put on alert by the recent emergence of Wuhan coronavirus (2019-nCoV) [1-4], which is a reminiscent of the severe acute respiratory syndrome (SARS) coronavirus (CoV) outbreak eighteen years ago [5-7]. During the 2002-2003-outbreak, SARS-CoV is the agent of severe acute respiratory syndrome [8-10]. From a molecular infectious mechanism point of view, the spike protein of SARS-CoV attaches the virus to its cellular receptor, angiotensin-converting enzyme 2 (ACE2) [11-13], which is mediated by the receptor binding domain (RBD) of the spike protein [14-17].

As stated in a recently reported paper [6], one of the goals of SARS-CoV research was to build an atomic-level iterative framework of virus-receptor interactions to facilitate epidemic surveillance, predict species-specific receptor usage, and identify potential animal hosts and animal models of viruses. To date, there has been already a series of structural studies on the receptor recognition by SARS-CoV, which identified key atomic-level interactions between SARS-CoV spike protein and ACE2 [6,18-20], and also uncovered atomic details at the interface between the two proteins, which helps clarify the importance of residue changes that facilitate efficient cross-species infection and human-to-human transmission, and suggesting ways to make truncated disulfide-stabilized RBD variants for vaccine designs [8,21-23]. 


\section{Motivation}

Since the SARS-CoV outbreak eighteen years ago [24], extensive structural analysis have revealed key atomic-level interactions between SARS-CoV spike protein RBD and ACE2 [6,18-20,25-27]. To date, however, their has not been any report yet of a comprehensive analysis of SARS-CoV spike protein RBD-related structures. Therefore, this article aims to address this issue from a structural point of view, and aims to identify electrostatic hot spots at the binding interface between SARS-CoV spike protein RBD and its receptor ACE2.

\section{Materials and Methods}

As of February 13, 2020, the Protein Data Bank (PDB) [28] hosts only 19 SARS spike protein receptor-binding domain-related experimental structures, with their PDB IDs including 2AJF, 2DD8, 2GHV, 2GHW, 3BGF, 3D0G, 3D0H, 3D0I, 3SCI, 3SCJ, 3SCK, 3SCL, 5X4R, 5X4S, 5X58, 5X59, 5X5B, 5X5C, 5X5F. Among the 19 experimental structures, 14 are X-ray crystal structures while the other five are electron microscopy structures. Furthermore, Among the 19 experimental structures, four are MERS-CoV-related structure, while the other 15 are SARS-CoV-related structures (Table 1), with their PDB IDs including 2AJF, 2DD8, 2GHV, 2GHW, 3BGF, 3D0G, 3D0H, 3D0I, 3SCI, 3SCJ, 3SCK, 3SCL, 5X4S, 5X58, 5X5B.

\begin{tabular}{|c|c|c|}
\hline No. & PDB ID & Structure Title \\
\hline 1 & 2AJF & Structure of SARS coronavirus spike receptor-binding domain complexed with its receptor \\
\hline 2 & 2DD8 & Crystal Structure of SARS-CoV Spike Receptor-Binding Domain Complexed with Neutralizing Antibody \\
\hline 3 & 2GHV & Crystal structure of SARS spike protein receptor binding domain (apo state) \\
\hline 4 & 2GHW & Crystal structure of SARS spike protein receptor binding domain in complex with a neutralizing antibody, $80 \mathrm{R}$ \\
\hline 5 & 3BGF & X-ray crystal structure of the SARS coronavirus spike receptor binding domain in complex with F26G19 Fab \\
\hline 6 & 3D0G & $\begin{array}{l}\text { Crystal structure of spike protein receptor-binding domain from the } \\
\text { 2002-2003 SARS coronavirus human strain complexed with human-civet chimeric receptor ACE2 }\end{array}$ \\
\hline 7 & $3 \mathrm{DOH}$ & $\begin{array}{l}\text { Crystal structure of spike protein receptor-binding domain from the } \\
\text { 2002-2003 SARS coronavirus civet strain complexed with human-civet chimeric receptor ACE2 }\end{array}$ \\
\hline 8 & 3D0I & $\begin{array}{l}\text { Crystal structure of spike protein receptor-binding domain from the } \\
\text { SARS coronavirus civet strain complexed with human-civet chimeric receptor ACE2 }\end{array}$ \\
\hline 9 & 3SCI & $\begin{array}{l}\text { Crystal structure of spike protein receptor-binding domain from a predicted } \\
\text { SARS coronavirus human strain complexed with human receptor ACE2 }\end{array}$ \\
\hline 10 & $3 \mathrm{SCJ}$ & $\begin{array}{l}\text { Crystal structure of spike protein receptor-binding domain from a predicted } \\
\text { SARS coronavirus civet strain complexed with human receptor ACE2 }\end{array}$ \\
\hline 11 & 3SCK & $\begin{array}{l}\text { Crystal structure of spike protein receptor-binding domain from a predicted } \\
\text { SARS coronavirus civet strain complexed with human-civet chimeric receptor ACE2 }\end{array}$ \\
\hline 12 & 3SCL & $\begin{array}{l}\text { Crystal structure of spike protein receptor-binding domain from SARS } \\
\text { coronavirus epidemic strain complexed with human-civet chimeric receptor ACE2 }\end{array}$ \\
\hline 13 & $5 X 4 S$ & Structure of the N-terminal domain (NTD) of SARS-CoV spike protein (apo state) \\
\hline 14 & $5 \times 58$ & Prefusion structure of SARS-CoV spike glycoprotein (apo state), conformation 1, \\
\hline 15 & 5X5B & Prefusion structure of SARS-CoV spike glycoprotein (apo state), conformation 2 \\
\hline
\end{tabular}

Table 1. SARS spike protein receptor-binding domain-related structures inside Protein Data Bank as of February 17, 2020. All the structures were retrieved from the PDB website with a text search SARS spike protein receptor-binding domain.

After the 19 structures were accessed and downloaded directly from the PDB website [28], a comprehensive set of salt bridging analysis was carried out as described in [29] previously. Nonetheless, no hydrogen bonding network analysis was carried out here because usually hydrogen atoms are missing from experimentally determined biomolecular structures solved using X-ray crystallography.

Here, the molecular visualization software PyMol [30] was used for preparing structural figures to illustrate the structurally identified electrostatic hot spots of SARS-CoV spike protein complexed with ACE2 or its neutralizing antibodies. 


\section{Results}

4.1. Structurally identified electrostatic hot spots for SARS-CoV Spike Protein to be complexed with ACE2 and its neutralizing antibodies

First, for all experimental structures in Table 1, Table 2 presents a list of residue pairs, i.e., structurally identified electrostatic hot spots for SARS-CoV spike protein to be complexed with ACE2 and its neutralizing antibodies. In Table 2, each residue pair is associated with at least one salt bridge at the interface of the complex structure of the SARS-CoV spike protein and its receptor ACE2 or its neutralizing antibodies.

\begin{tabular}{|l|l|l|}
\hline PDB ID & Structurally identified electrostatic hot spots (residue pair) \\
\hline 2AJF & A_LYS_534 + B_ASP_431, B_LYS_419 + A_Glu_536, E_Arg_426 + A_Glu_329, F_Arg_426 + B_Glu_329 \\
\hline 2DD8 & H_LYS_129 + L_Glu_212, H_LYS_209 + L_Glu_124, L_LYS_130 + H_ASP_144, S_Arg_395 + L_ASP_95A \\
\hline 2GHW & B_Arg_162 + A_ASP_480, D_Arg_162 + C_ASP_480 \\
\hline 3BGF & S_Arg_426 + H_ASP_56, S_LYS_439 + A_ASP_480, A_LYS_439 + S_ASP_480, H_LYS_210 + L_Glu_123 \\
\hline 3D0G & B_LYS_419 + A_Glu_536 \\
\hline 3D0H & B_LYS_419 + A_Glu_536, E_LYS_479 + A_Glu_35, F_LYS_479 + B_Glu_35 \\
\hline 3D0I & B_LYS_419 + A_Glu_536, E_Arg_479 + A_Glu_35, F_Arg_479 + B_Glu_35 \\
\hline 3SCI & B_LYS_419 + A_Glu_536, E_Arg_426 + A_Glu_329, F_Arg_426 + B_Glu_329 \\
\hline 3SCJ & B_LYS_419 + A_Glu_536, E_Arg_426 + A_Glu_329, E_Arg_479 + A_ASP_38, F_Arg_426 + B_Glu_329, F_Arg_479 + B_ASP_38 \\
\hline 3SCK & B_LYS_419 + A_Glu_536, E_Arg_426 + A_Glu_329, E_Arg_479 + A_Glu_35, F_Arg_479 + B_Glu_35 \\
\hline 3SCL & B_LYS_419 + A_Glu_536, E_Arg_426 + A_Glu_329 \\
\hline 5X58 & A_LYS_221 + C_Glu_502, A_LYS_836 + C_ASP_554, A_Arg_977 + B_ASP_976, A_Arg_1001 + C_Glu_999, \\
& A_Arg_1021 + B_Glu_1013, B_LYS_221 + A_Glu_502, B_LYS_836 + A_ASP_554, B_Arg_977 + C_ASP_976, \\
& B_Arg_1001 + A_Glu_999, B_Arg_1021 + C_Glu_1013, C_LYS_221 + B_Glu_502, C_LYS_836 + B_ASP_554, \\
& C_Arg_977 + A_ASP_976, C_Arg_1001 + B_Glu_999, C_Arg_1021 + A_Glu_1013 \\
\hline 5X5B & A_Arg_977 + B_ASP_976, A_Arg_1001 + C_Glu_999, A_Arg_1021 + B_Glu_1013, A_Arg_1073 + B_ASP_1100, \\
& B_Arg_1001 + A_Glu_999, B_Arg_1021 + C_Glu_1013, C_LYS_221 + B_Glu_502, C_Arg_1001 + B_Glu_999, \\
& C_Arg_1021 + A_Glu_1013, C_Arg_1073 + A_ASP_1100
\end{tabular}

Table 2. Structurally identified electrostatic hot spots for SARS-CoV spike protein to be complexed with ACE2 and its neutralizing antibodies. In this table, the residue naming scheme is chain ID_residue name_residue number.

4.2. Electrostatic hot spots for SARS-CoV spike protein to be complexed with ACE2: an experimentally identified example

PDB ID 2AJF (2AJF.pdb) represents a structure of SARS-CoV spike protein RBD complexed with its receptor (Table 1). With the structural analysis previously described in [29], a set of Glu329-Arg426 side chain salt bridges were identified at the interface of the complex structure of SARS SARS-CoV spike protein RBD (chain F of 2AJF) and ACE2 (chain B), as shown in Figures 1, 2, 3 and 4 . In total, four salt bridges formed (PDB ID: 2AJF) between the side chains of Arg426 of SARS-CoV spike protein RBD and Glu329 of ACE2, the details of which are included in Table 3 as below.

\begin{tabular}{|l|c|c|c|c|c|}
\hline PDB ID & Residue A & Atom A & Residue B & Atom B & Distance (Å) \\
\hline 2AJF & F_ARG_426 & NH1 & B_GLU_329 & OE1 & 3.890 \\
\hline 2AJF & F_ARG_426 & NH1 & B_GLU_329 & OE2 & 3.381 \\
\hline 2AJF & F_ARG_426 & NH2 & B_GLU_329 & OE1 & 2.717 \\
\hline 2AJF & F_ARG_426 & NH2 & B_GLU_329 & OE2 & 2.911 \\
\hline
\end{tabular}

Table 3. A interfacial Arg426-Glu329 salt bridge is structurally identified from 2AJF.pdb. In this table, the residue naming scheme is Chain ID_residue name_residue number. 


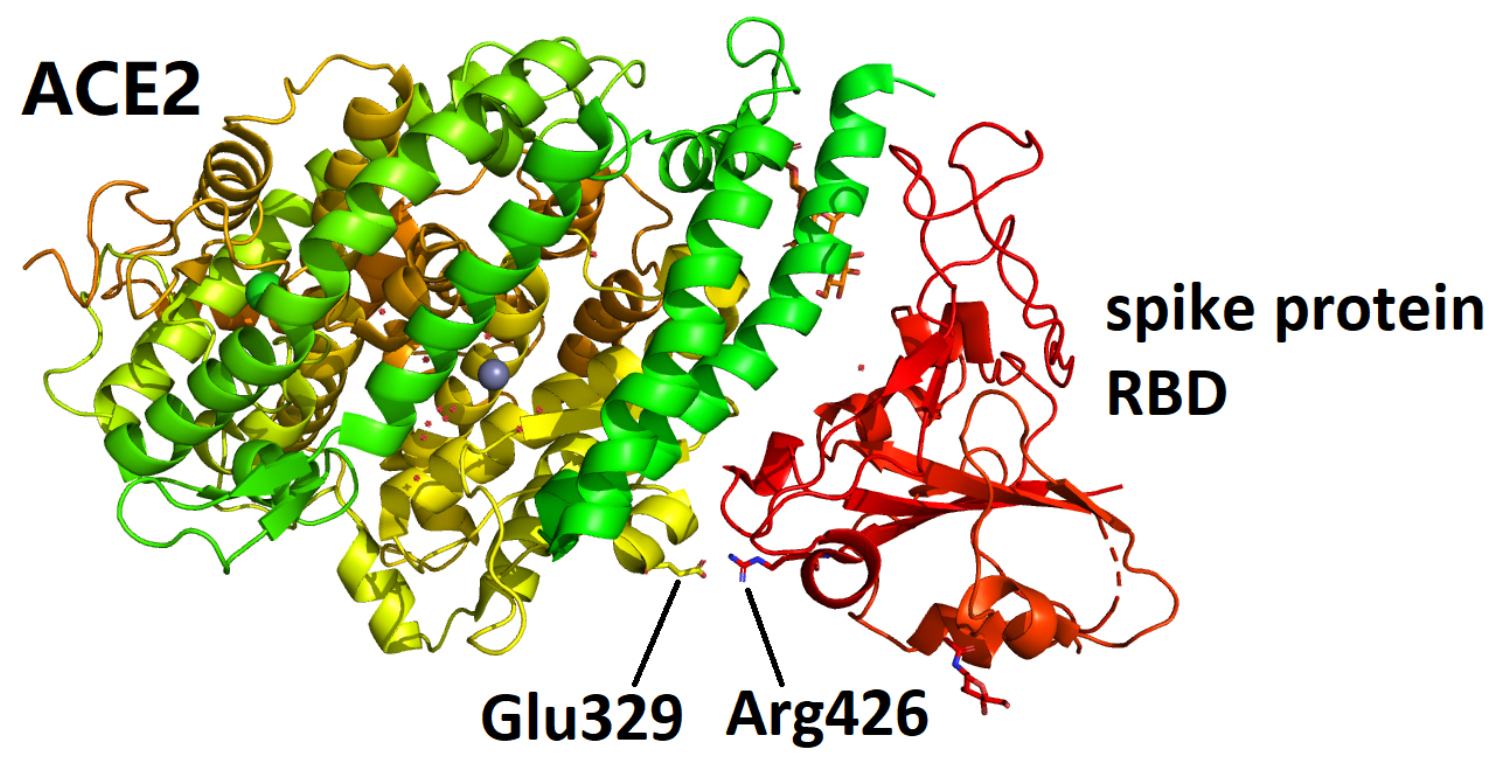

Figure 1. An overview of the interfacial Arg426-Glu329 salt bridge structurally identified from 2AJF.pdb. The details of this salt bridge are included in Table 3 and Tables 20 and 263 in supplementary file supplementary.pdf. This figure is prepared using PyMol [30].

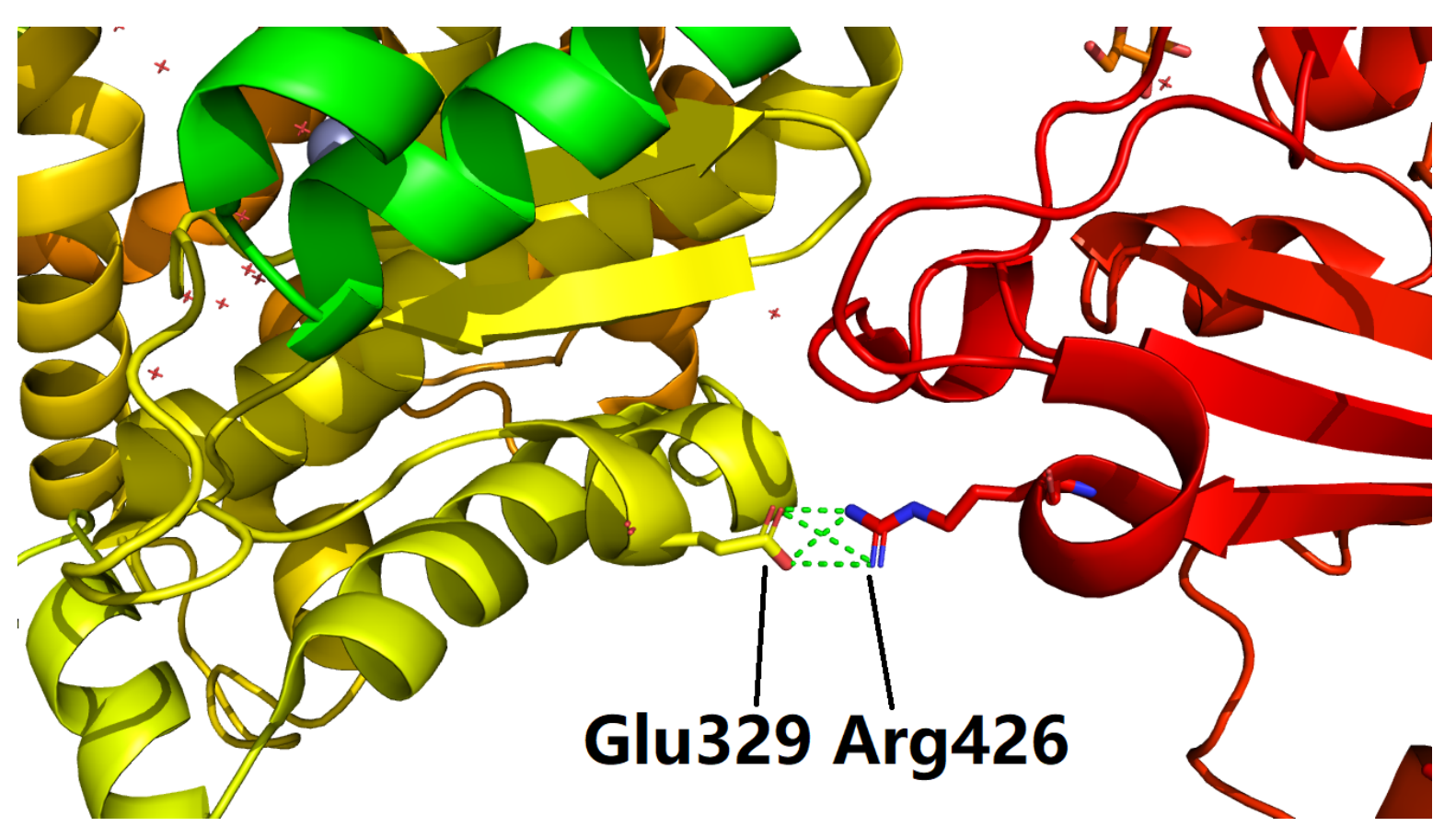

Figure 2. A close view of the interfacial Arg426-Glu329 salt bridge structurally identified from 2AJF.pdb, the four green dotted lines represent the four side chain salt bridges. The details of this salt bridge are included in Table 3 and Tables 20 and 263 in supplementary file supplementary.pdf. This figure is prepared using PyMol [30]. 


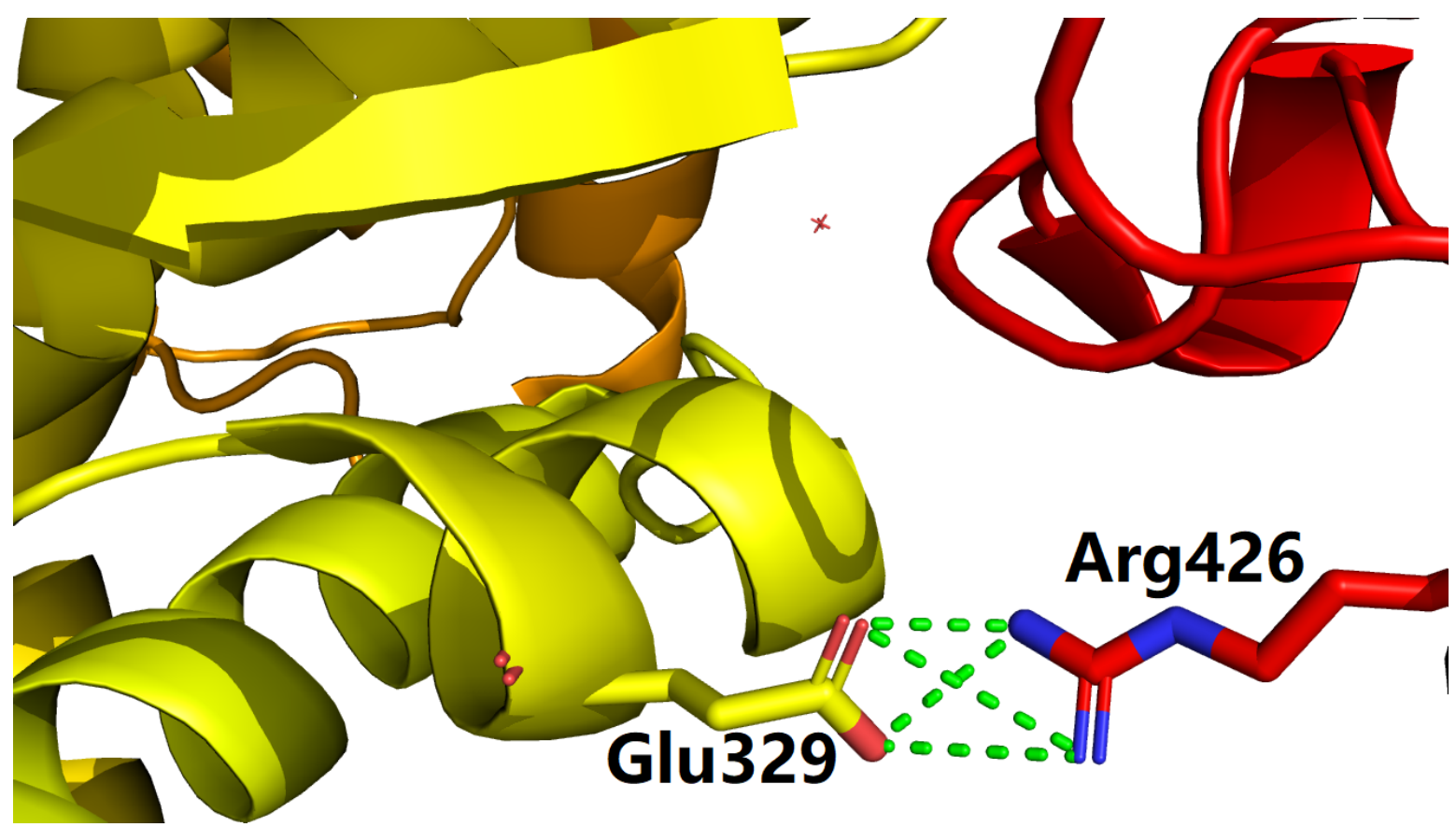

Figure 3. A detailed view of the interfacial Arg426-Glu329 salt bridge structurally identified from 2AJF.pdb, the four green dotted lines represent the four side chain salt bridges. The details of this salt bridge are included in Table 3 and Tables 20 and 263 in supplementary file supplementary.pdf. This figure is prepared using PyMol [30].

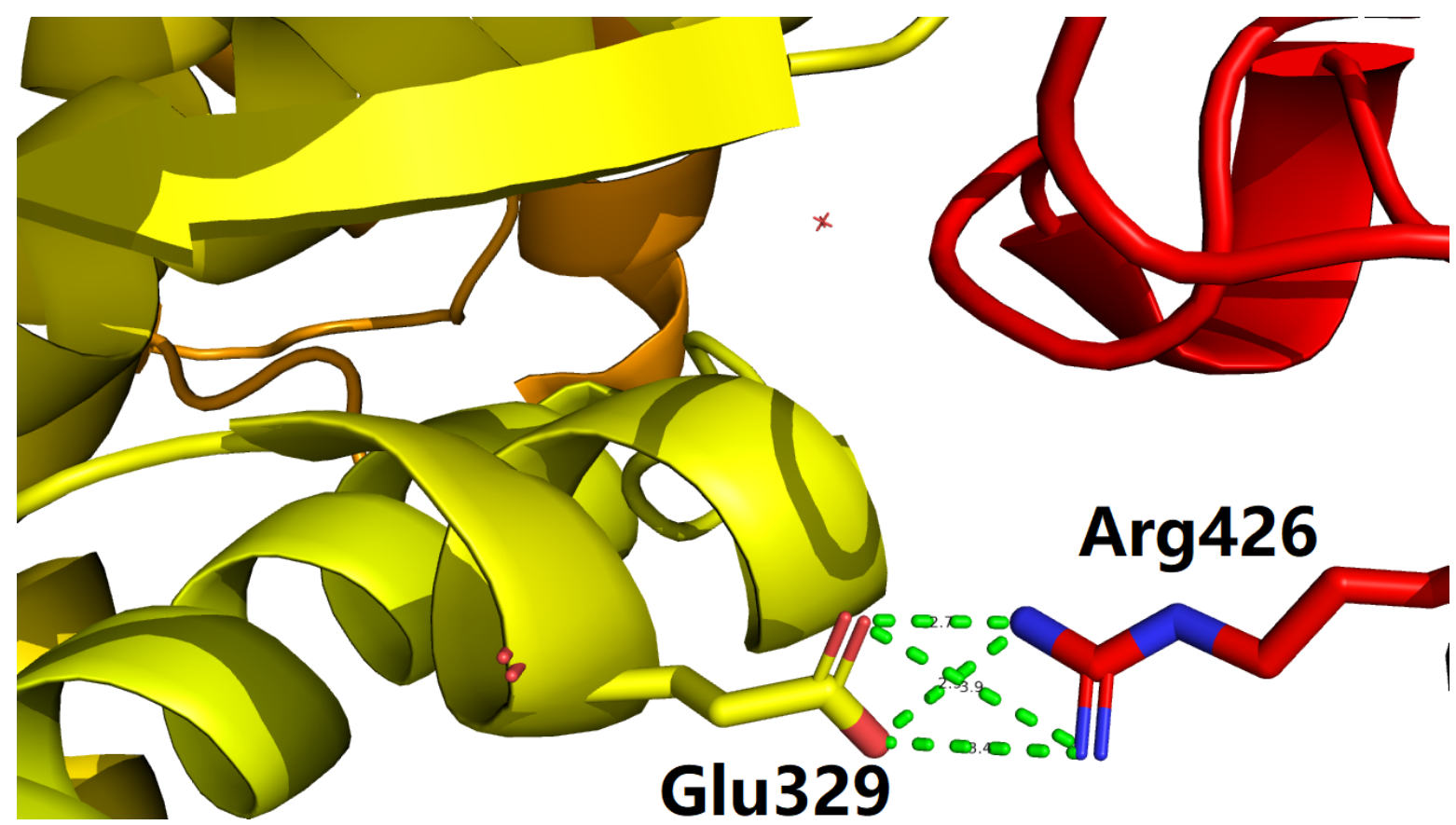

Figure 4. A detailed view of the interfacial Arg426-Glu329 salt bridge structurally identified from 2AJF.pdb, the four green dotted lines represent the four side chain salt bridges with inter-atomic distances being 2.7, 3.4, 3.9 and $2.9 \AA$, respectively. The details of this salt bridge are included in Table 3 and Tables 20 and 263 in supplementary file supplementary.pdf. This figure is prepared using PyMol [30]. 
4.3. Electrostatic hot spots for SARS-CoV spike protein to be complexed with its antibodies: an experimentally identified example

PDB ID 3BGF (3BGF.pdb) represents an X-ray crystal structure (Table 1) of the SARS coronavirus spike receptor binding domain in complex with the Fab fragment of a neutralizing mouse monoclonal antibody, F26G19 [27]. With the structural analysis previously described in [29], two Arg426-Asp56 side chain salt bridges were identified at the interface of the complex structure of SARS SARS-CoV spike protein RBD (chain S of 3BGF) and F26G19 (chain H of 3BGF), as shown in Figures 5, 6 and 7. In total, two salt bridges formed (PDB ID: 3BGF) between the side chains of Arg426 of SARS-CoV spike protein RBD and Asp56 of F26G19 Fab fragment, the details of which are included in Table 4 as below.

\begin{tabular}{|l|c|c|c|c|c|}
\hline PDB ID & Residue A & Atom A & Residue B & Atom B & Distance (Å) \\
\hline 3BGF & S_ARG_426 & NH1 & H_ASP_56 & OD1 & 3.504 \\
\hline 3BGF & S_ARG_426 & NH1 & H_ASP_56 & OD2 & 2.403 \\
\hline
\end{tabular}

Table 4. A interfacial Arg426-Asp56 salt bridge is structurally identified from 3BGF.pdb. In this table, the residue naming scheme is Chain ID_residue name_residue number.

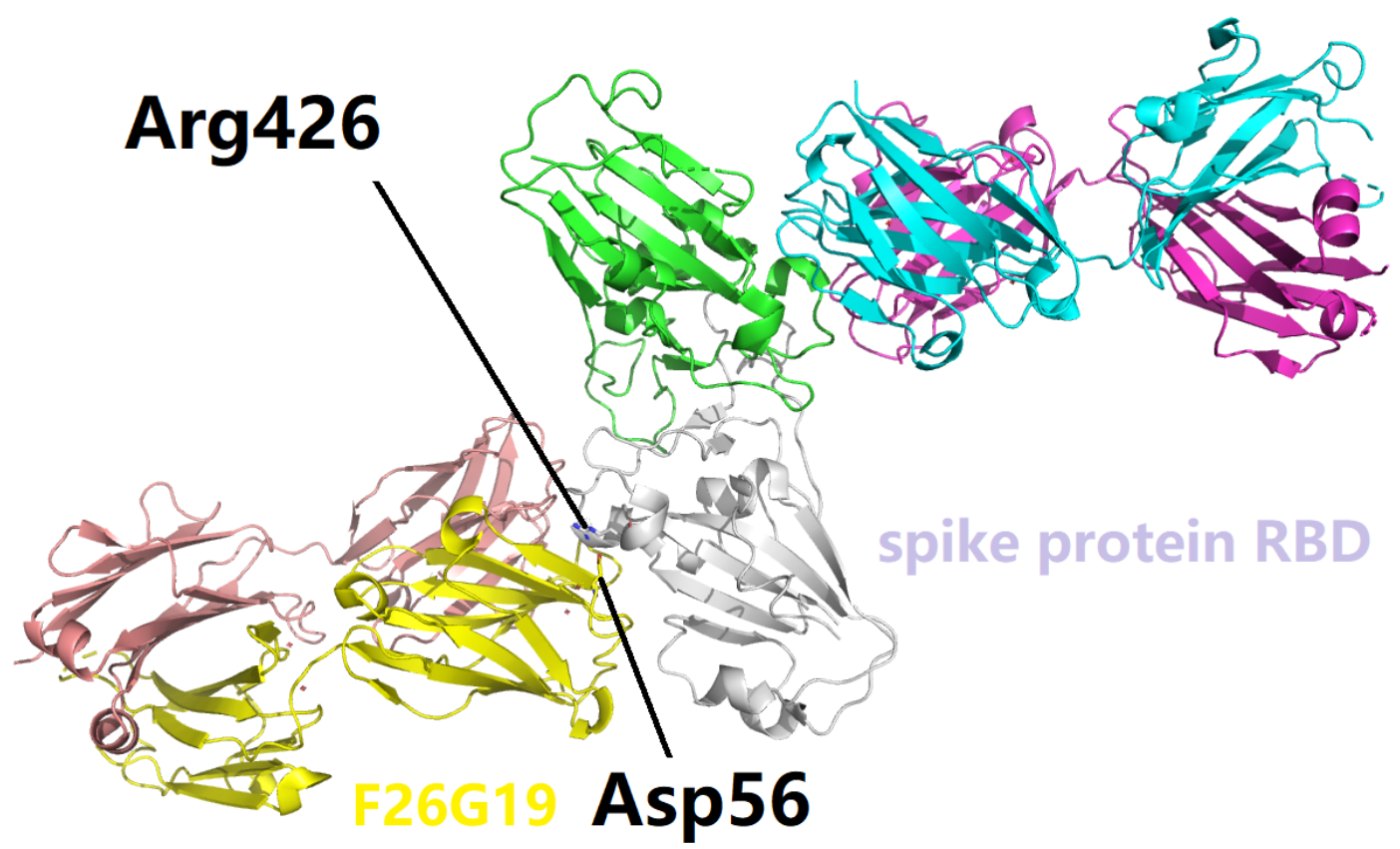

Figure 5. An overview of the interfacial Arg426-Asp56 salt bridge structurally identified from 3BGF.pdb, representing a complex structure of SARS SARS-CoV spike protein RBD (chain S of 3BGF, silver) and F26G19 (chain H of 3BGF, yellow). The details of this salt bridge are included in Table 4. This figure is prepared using PyMol [30]. 


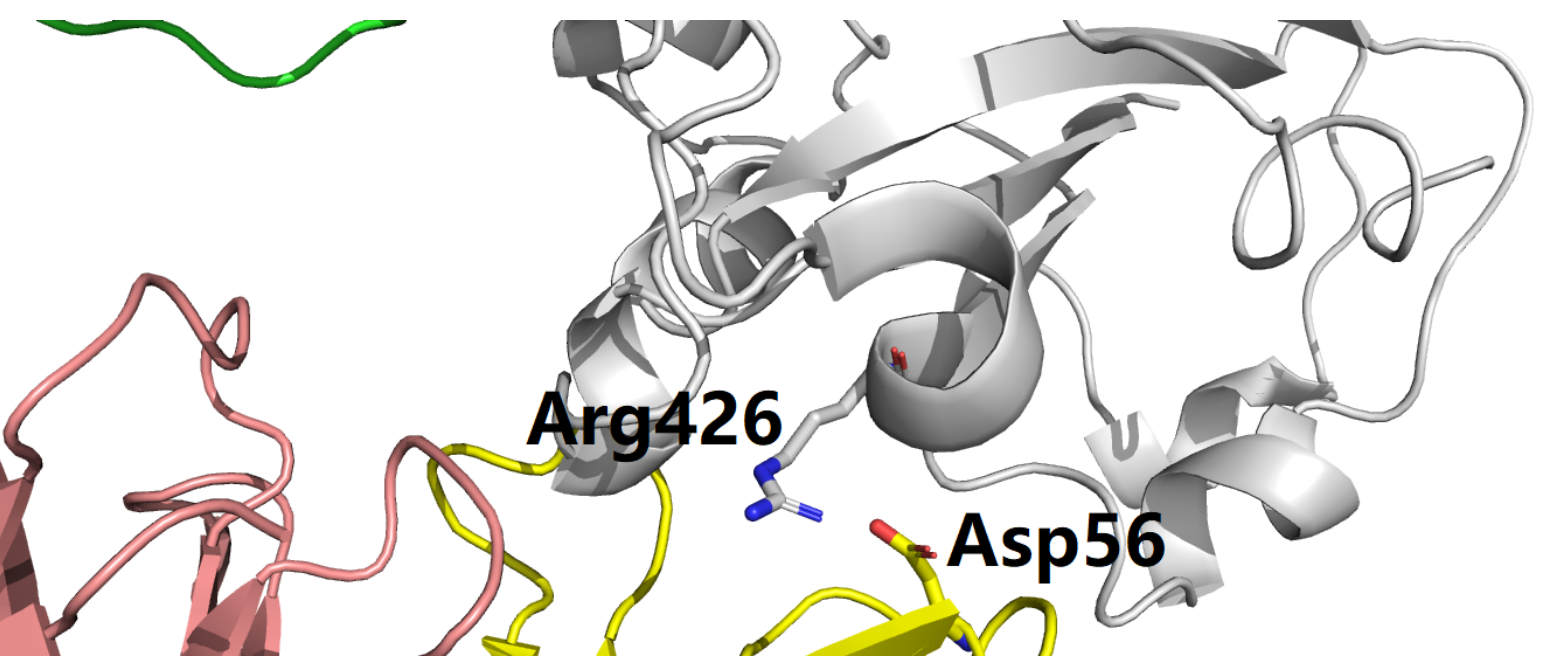

Figure 6. A close view of the interfacial Arg426-Asp56 salt bridge structurally identified from 3BGF.pdb, representing a complex structure of SARS SARS-CoV spike protein RBD (chain S of 3BGF, silver) and F26G19 (chain H of 3BGF, yellow). The details of this salt bridge are included in Table 4. This figure is prepared using PyMol [30].

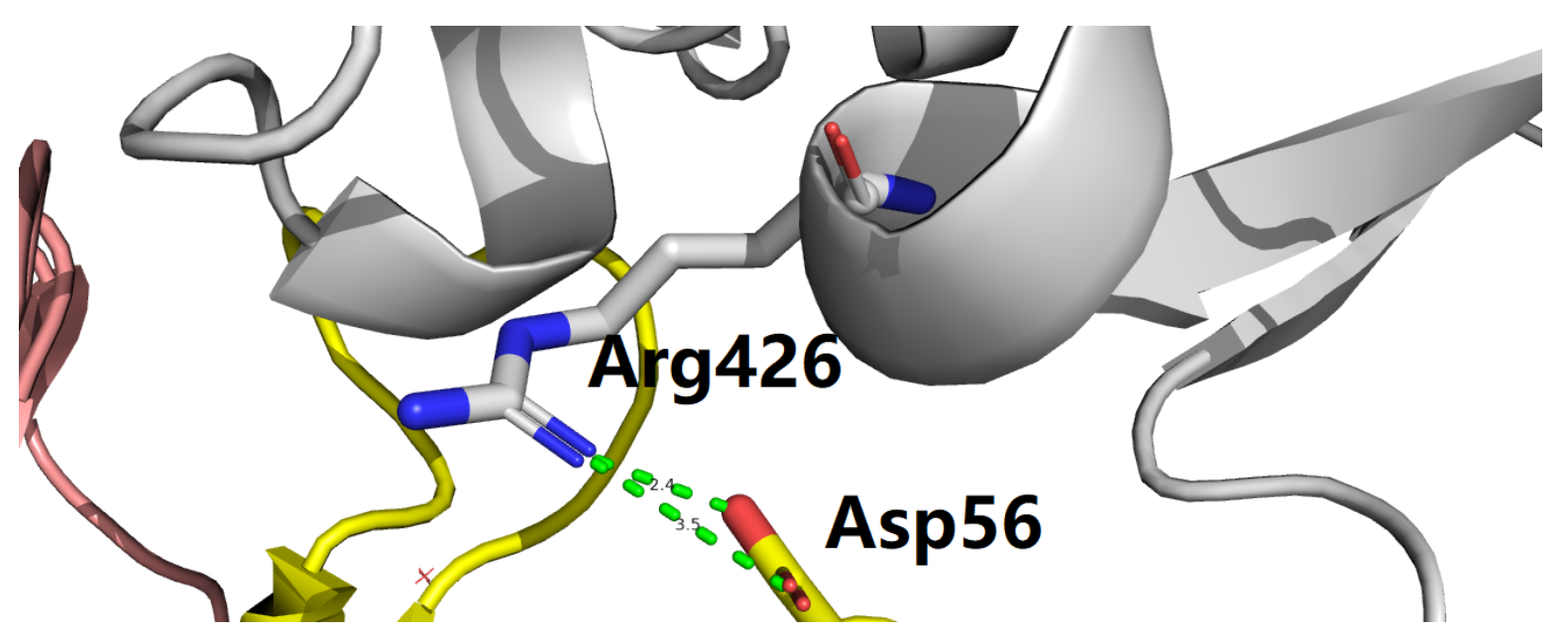

Figure 7. A detailed view of the interfacial Arg426-Asp56 salt bridge structurally identified from 3BGF.pdb, representing a complex structure of SARS SARS-CoV spike protein RBD (chain S of 3BGF, silver) and F26G19 (chain H of 3BGF, yellow). In this figure, the two green dotted lines represent the two side chain salt bridges with inter-atomic distances being 2.4 and $3.5 \AA$, respectively (Table 4). The details of this salt bridge are included in Table 4. This figure is prepared using PyMol [30]. 
Moreover, this article reports a structurally identified action mechanism of how the F26G19 antibody exerts its biological function of neutralizing the SARS-CoV via disrupting the interaction between the SARS-CoV spike protein RBD and its receptor ACE2. Specifically, as shown by Figure 8, PDB ID 2AJF (2AJF.pdb) represents a structure of SARS-CoV spike protein RBD complexed with its receptor (Table 1), where an interfacial side chain salt bridge (Glu329-Arg426) was structurally identified. Quite intriguingly, an interfacial side chain salt bridge was also structurally observed for Arg426 of SARS-CoV spike protein RBD, i.e., the interfacial Asp56-Arg426 side chain salt bridge between SARS-CoV spike protein RBD and its antibody F26G19 (PDB ID: 3BGF) [27]. This interesting finding reveals a structural axis of how the F26G19 antibody exerts its biological function of neutralizing the SARS-CoV, where the Asp56 of F26G19 binds to the Arg426 of SARS-CoV spike protein RBD, competing against the electrostatic interaction between the Arg426 of SARS-CoV spike protein RBD and the Glu329 of the SARS-CoV spike protein RBD receptor ACE2, and thereby performing its neutralizing function via disrupting the interaction between SARS-CoV spike protein RBD and its receptor ACE2.

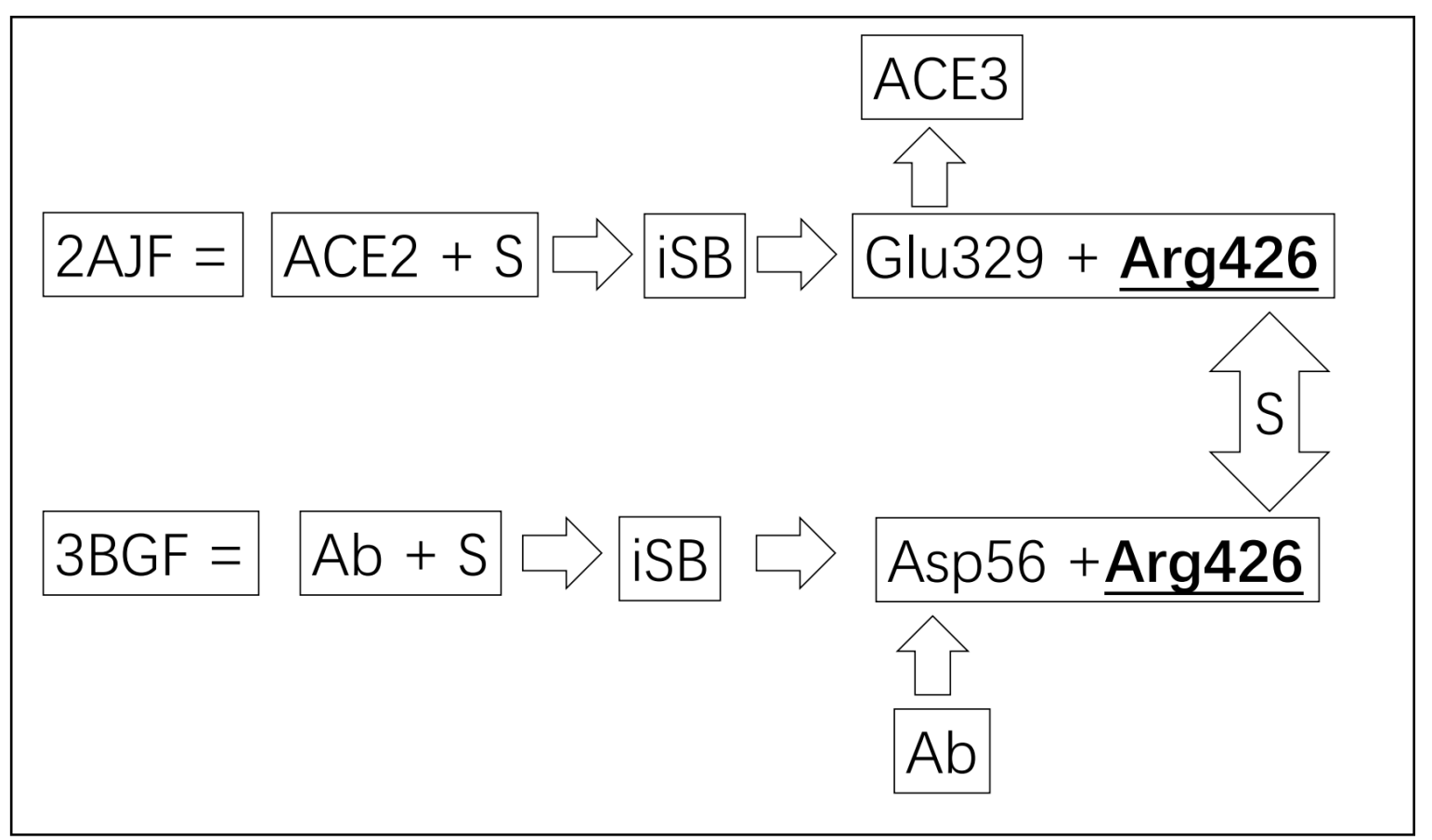

Figure 8. A structural axis of how the F26G19 antibody exerts its biological function of neutralizing the SARS-CoV. In this figure, $\mathbf{S}$ represents the SARS-CoV spike protein, iSB represents the structurally identified interfacial side chain salt bridges, Ab represents the F26G19 antibody. 
4.4. Electrostatic hot spots for SARS-CoV spike protein to be complexed with ACE2: another experimentally identified example

PDB ID 3D0I (3D0I.pdb) represents a crystal structure of spike protein RBD from the SARS coronavirus civet strain complexed with human-civet chimeric receptor ACE2 (Table 1). With the structural analysis previously described in [29], four Arg479-Glu35 side chain salt bridges were identified at the interface of the complex structure of SARS SARS-CoV spike protein RBD (chains E and F, of 3D0I) and ACE2 (chains A and B of 3D0I), as shown in Figures 9 and 10. In total, four salt bridges formed (PDB ID: 3D0I) between the side chains of Arg479 of SARS-CoV spike protein RBD and Glu35 of ACE2, the details of which are included in Table 5 as below.

\begin{tabular}{|l|c|c|c|c|c|}
\hline PDB ID & Residue A & Atom A & Residue B & Atom B & Distance (̊̊) \\
\hline 3D0I & E_ARG_479 & NH1 & A_GLU_35 & OE1 & 3.324 \\
\hline 3D0I & E_ARG_479 & NH2 & A_GLU_35 & OE1 & 2.730 \\
\hline 3D0I & F_ARG_479 & NH1 & B_GLU_35 & OE1 & 3.405 \\
\hline 3D0I & F_ARG_479 & NH2 & B_GLU_35 & OE1 & 2.961 \\
\hline
\end{tabular}

Table 5. A interfacial Arg479-Glu35 salt bridge is structurally identified from 3D0I.pdb. In this table, the residue naming scheme is Chain ID_residue name_residue number.

Furthermore, the Arg479-Glu35 side chains are the only ones for SARS SARS-CoV spike protein RBD (chains E and F, of 3D0I) and ACE2 (chains A and B of 3D0I), as shown in Figures 9 and 10, as shown by a comprehensive set of structural analysis of all the 19 (Table 1) structures (Tables 6 and 7).

\begin{tabular}{|l|c|c|c|c|c|}
\hline PDB ID & Residue A & Atom A & Residue B & Atom B & Distance (̊) \\
\hline 3D0H & E_LYS_479 & NZ & A_Glu_35 & OE1 & 3.397 \\
\hline 3D0H & F_LYS_479 & NZ & B_Glu_35 & OE1 & 3.369 \\
\hline 3D0I & E_Arg_479 & NH1 & A_Glu_35 & OE1 & 3.324 \\
\hline 3D0I & E_Arg_479 & NH2 & A_Glu_35 & OE1 & 2.730 \\
\hline 3D0I & F_Arg_479 & NH1 & B_Glu_35 & OE1 & 3.405 \\
\hline 3D0I & F_Arg_479 & NH2 & B_Glu_35 & OE1 & 2.961 \\
\hline 3SCK & E_Arg_479 & NH1 & A_Glu_35 & OE1 & 2.498 \\
\hline 3SCK & F_Arg_479 & NH1 & B_Glu_35 & OE1 & 2.750 \\
\hline
\end{tabular}

Table 6. Interfacial Glu35-specific salt bridging networks within the PDB entries. In this table, the residue naming scheme is chain ID_residue name_residue number.

\begin{tabular}{|l|c|c|c|c|c|}
\hline PDB ID & Residue A & Atom A & Residue B & Atom B & Distance ( $)$ \\
\hline 3D0I & E_Arg_479 & NH1 & A_Glu_35 & OE1 & 3.324 \\
\hline 3D0I & E_Arg_479 & NH2 & A_Glu_35 & OE1 & 2.730 \\
\hline 3D0I & F_Arg_479 & NH1 & B_Glu_35 & OE1 & 3.405 \\
\hline 3D0I & F_Arg_479 & NH2 & B_Glu_35 & OE1 & 2.961 \\
\hline 3SCJ & E_Arg_479 & NH2 & A_ASP_38 & OD2 & 2.575 \\
\hline 3SCJ & F_Arg_479 & NH2 & B_ASP_38 & OD2 & 2.718 \\
\hline 3SCK & E_Arg_479 & NH1 & A_Glu_35 & OE1 & 2.498 \\
\hline 3SCK & F_Arg_479 & NH1 & B_Glu_35 & OE1 & 2.750 \\
\hline
\end{tabular}

Table 7. Interfacial Arg479-specific salt bridging networks within the PDB entries. In this table, the residue naming scheme is chain ID_residue name_residue number.

To date, no structural axis (Figure 8) has been reported yet for PDB ID 3D0I, i.e., there is not yet an experimental complex structure of SARS-CoV spike RBD and its antibody, where an interfacial side chain salt bridge is associated with the Arg479 of SARS-CoV spike RBD and one certain residue of 
its antibody. Thus, this structurally identified Arg479-Glu35 salt bridge provides a useful clue for the design of antibody $[14,31-33]$ of SARS-CoV spike RBD in future.

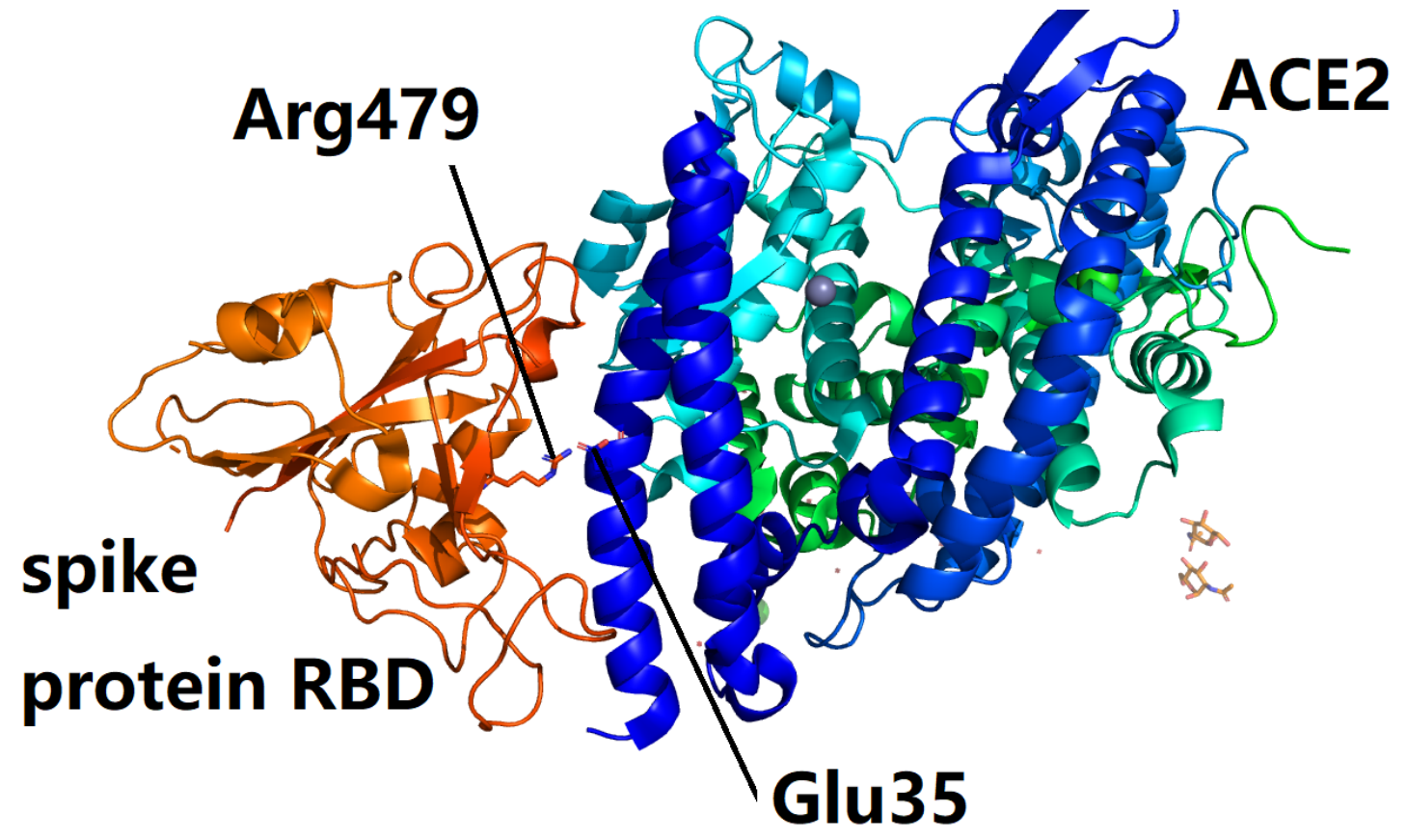

Figure 9. An overview of the interfacial Arg479-Glu35 salt bridge structurally identified from 3D0I.pdb, representing a complex structure of SARS SARS-CoV spike protein RBD (chains E and F of 3D0I, orange) and ACE2 (chain A of 3D0I, blue). This figure is prepared using PyMol [30].

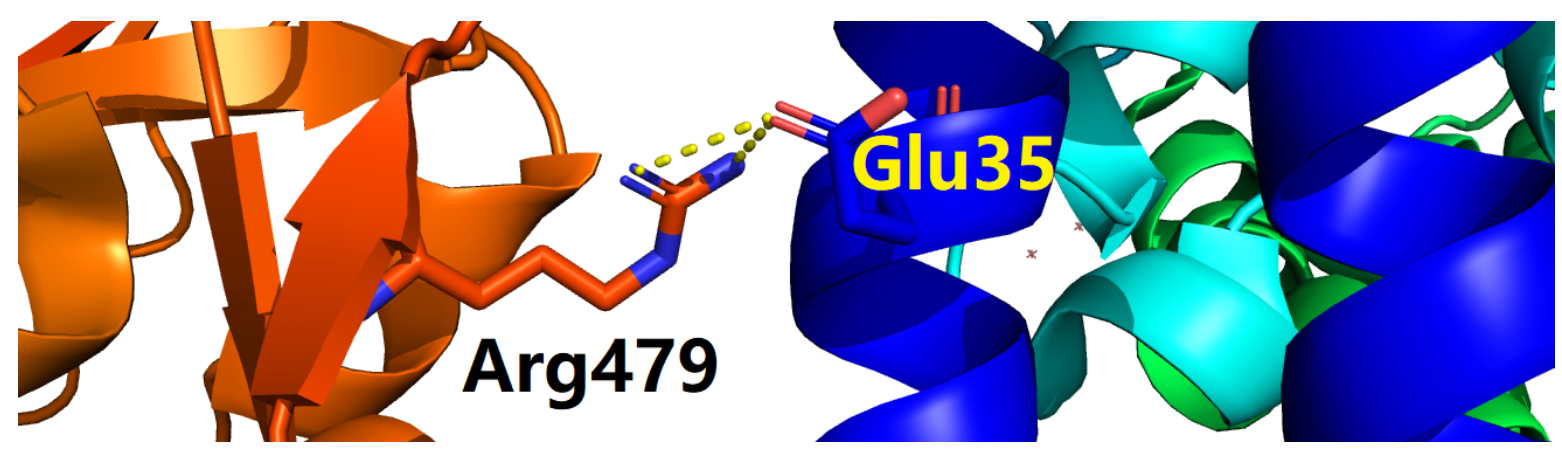

Figure 10. An detailed view of the interfacial Arg479-Glu35 salt bridge structurally identified from 3D0I.pdb, representing a complex structure of SARS SARS-CoV spike protein RBD (chains E and F of 3D0I, orange) and ACE2 (chain A of 3D0I, blue). In this figure, the two yellow dotted lines represent the two side chain salt bridges with inter-atomic distances being 2.7 and $3.3 \AA$, respectively. This figure is prepared using PyMol [30]. 


\section{Conclusion}

For the first time, this article reports a comprehensive set of structural electrostatic analysis of all SARS-CoV spike protein RBD-related structures as of February 13, 2020, along with all electrostatic hot spots for SARS-CoV spike protein to be complexed with ACE2 and its neutralizing antibodies.

1. This article identified a structural action mechanism of one antibody (F26G19) of SARS-CoV spike protein, where the Asp56 residue of F26G19 binds to the Arg426 of the SARS-CoV spike protein RBD, which breaks the interfacial Arg426-Glu329 salt bridges between ACE2 and the SARS-CoV spike protein RBD, as shown in Figures 1, 2, 3, 4, 5, 6, 7 and 8.

2. This article reports a structurally identified interfacial Glu35-Arg 479 salt bridge which helps stabilize the complex structure of ACE2 and the SARS-CoV spike protein RBD.

3. This article puts forward a hypothesis that a pair of electrostatic clips [29] exist at the interface between ACE2 and the SARS-CoV spike protein RBD, including both Arg426-Glu329 and His445-Glu23-Lys447 salt bridges, which is to be discussed below in detail.

Overall, the structurally identified electrostatic hot spots (Tables 2 and 8 ) here may prove useful for the design of SARS-CoV-neutralizing antibody [23,34-37].

\begin{tabular}{|c|c|c|}
\hline Number of salt bridges & Residue A & Residue B \\
\hline 22 & Arg426 & Glu329 \\
\hline 20 & Arg1001 & Glu999 \\
\hline 15 & Arg1021 & Glu1013 \\
\hline 15 & LYS419 & Glu536 \\
\hline 12 & Arg977 & ASP976 \\
\hline 6 & Arg479 & Glu35 \\
\hline 5 & LYS221 & Glu502 \\
\hline 3 & Arg395 & ASP95 \\
\hline 3 & LYS836 & ASP554 \\
\hline 2 & LYS439 & ASP480 \\
\hline 2 & LYS479 & Glu35 \\
\hline 2 & Arg426 & ASP56 \\
\hline 2 & Arg162 & ASP480 \\
\hline 2 & Arg479 & ASP38 \\
\hline 2 & LYS129 & Glu212 \\
\hline 2 & Arg1073 & ASP1100 \\
\hline 2 & LYS209 & Glu124 \\
\hline 1 & LYS210 & Glu123 \\
\hline 1 & LYS534 & ASP431 \\
\hline 1 & LYS130 & ASP144 \\
\hline
\end{tabular}

Table 8. Numbers of the structurally identified interfacial side chain salt bridging networks within the 15 SARS-CoV spike protein RBD-related structures (Table 1).

\section{Discussion}

Just with a naked eye inspection of Figures 1, 2, 3, 4 and 11, it looks possible that two structurally stabilizing electrostatic clips exist at the interface of the complex structure of SARS-CoV spike protein RBD and ACE2 (PDB ID: 2AJF, Table 9). Similarly, in 2017, a set of two electrostatic clips were structurally identified and reported to be important for the overall stability of the complex structure (PDB ID: 2LEH) of survival motor neuron protein (Gemin1) and Gemin2 [29,38].

Yet, for the 15 SARS-CoV-related structures (Table 1), with a special structural scanning of electrostatic interaction with a cutoff distance at $12 \AA$, instead of the normal cutoff at $4 \AA$, it appears not possible that two structurally stabilizing electrostatic clips exist at the interface of the complex structure 


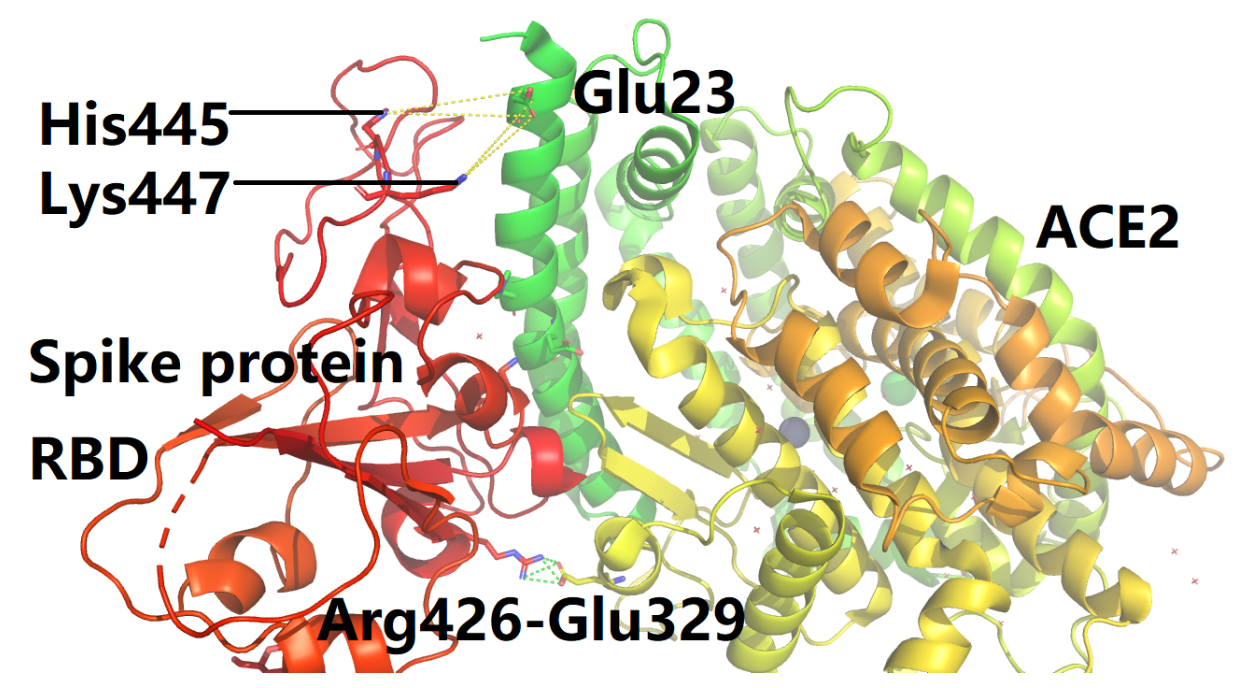

Figure 11. An overview of the experimental complex structure of SARS-CoV spike protein RBD and ACE2 (PDB ID: 2AJF). In this figure, the four green dotted lines represent the structurally identified salt bridges at the interface of SARS-CoV spike protein RBD and ACE2 (PDB ID: 2AJF), while the four yellow dotted lines $(11.906,11.869,10.486$ and $10.922 \AA$, respectively) represent the four hypothesized salt bridges at the interface of SARS-CoV spike protein RBD and ACE2 (PDB ID: 2AJF).

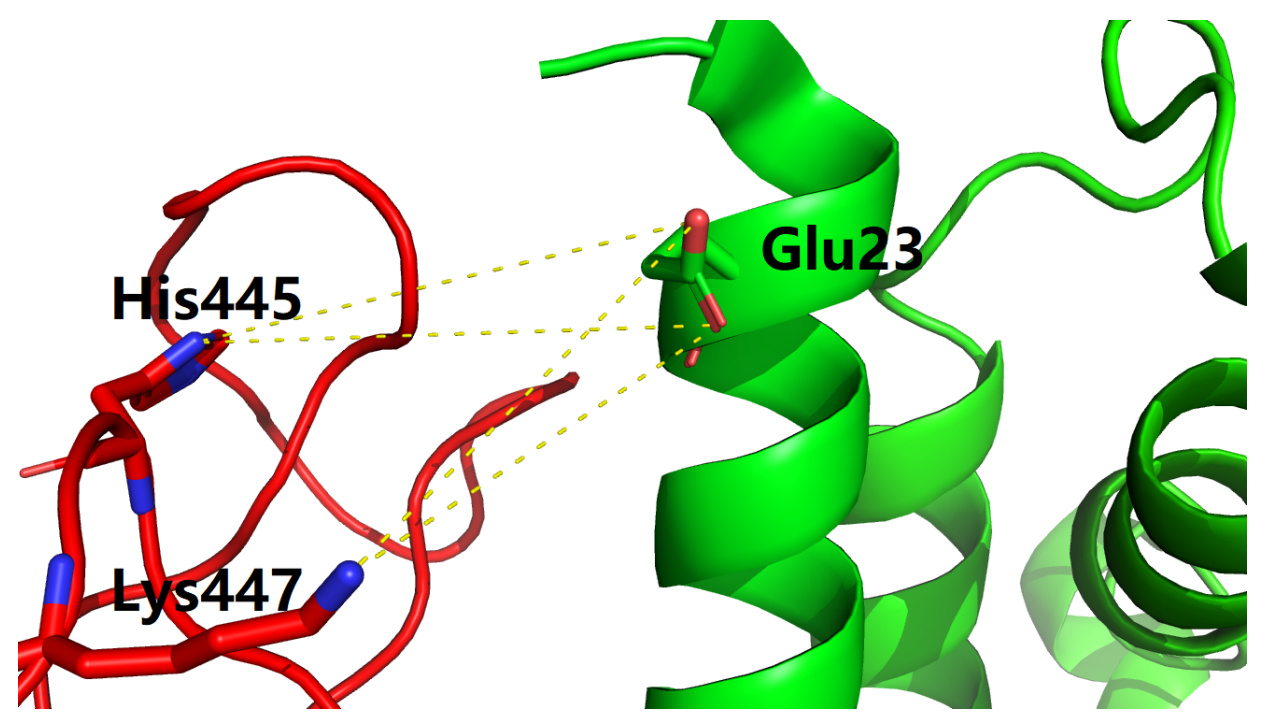

Figure 12. A close view of the experimental complex structure of SARS-CoV spike protein RBD and ACE2 (PDB ID: 2AJF). In this figure, the four yellow dotted lines (11.906, 11.869, 10.486 and $10.922 \AA$, respectively) represent the four hypothesized salt bridges at the interface of SARS-CoV spike protein RBD and ACE2 (PDB ID: 2AJF) 
of SARS-CoV spike protein RBD and ACE2 (PDB ID: 2AJF, Table 9), including only the structurally identified salt bridges at the interface of SARS-CoV spike protein RBD and ACE2 (PDB ID: 2AJF), while the electrostatic interactions between His445, Glu23 and Lys447 do not seem experimentally possible, as shown in Figures 11 and 12 and Table 9, because the side chains of the two positively charged amino acid residues are way too far away from that of the Glu23 of ACE2 (PDB ID:2AJF).

\begin{tabular}{|c|c|c|c|c|c|}
\hline PDB ID & Residue A & Atom A & Residue B & Atom B & Distance ( $(\AA)$ \\
\hline $2 \mathrm{AJF}$ & B_HIS_34 & ND1 & F_ASP_393 & OD1 & 10.496 \\
\hline $2 \mathrm{AJF}$ & B_HIS_34 & ND1 & F_ASP_393 & OD2 & 10.237 \\
\hline $2 \mathrm{AJF}$ & B_HIS_34 & NE2 & F_ASP_392 & OD2 & 11.817 \\
\hline $2 \mathrm{AJF}$ & B_HIS_34 & NE2 & F_ASP_393 & OD1 & 8.402 \\
\hline $2 \mathrm{AJF}$ & B_HIS_34 & NE2 & F_ASP_393 & OD2 & 8.179 \\
\hline $2 \mathrm{AJF}$ & B_HIS_34 & NE2 & F_ASP_407 & OD2 & 11.762 \\
\hline $2 \mathrm{AJF}$ & B_HIS_34 & NE2 & F_ASP_480 & OD1 & 11.948 \\
\hline $2 \mathrm{AJF}$ & B_LYS_353 & $\mathrm{NZ}$ & F_ASP_392 & OD2 & 11.184 \\
\hline 2AJF & B_LYS_353 & $\mathrm{NZ}$ & F_ASP_393 & OD1 & 11.785 \\
\hline $2 \mathrm{AJF}$ & B_LYS_353 & NZ & F_ASP_393 & OD2 & 10.430 \\
\hline $2 \mathrm{AJF}$ & B_LYS_353 & $\mathrm{NZ}$ & F_ASP_480 & OD1 & 10.342 \\
\hline $2 \mathrm{AJF}$ & B_LYS_353 & NZ & F_ASP_480 & OD2 & 9.775 \\
\hline $2 \mathrm{AJF}$ & B_Arg_393 & NH1 & F_ASP_392 & OD2 & 10.889 \\
\hline $2 \mathrm{AJF}$ & B_Arg_393 & $\mathrm{NH} 2$ & F_ASP_392 & OD1 & 11.808 \\
\hline 2AJF & B_Arg_393 & $\mathrm{NH} 2$ & F_ASP_392 & OD2 & 9.605 \\
\hline 2AJF & B_Arg_393 & $\mathrm{NH} 2$ & F_ASP_393 & OD1 & 11.944 \\
\hline $2 \mathrm{AJF}$ & F_LYS_390 & NZ & B_ASP_30 & OD1 & 11.110 \\
\hline $2 \mathrm{AJF}$ & F_LYS_390 & NZ & B_ASP_30 & OD2 & 11.666 \\
\hline $2 \mathrm{AJF}$ & F_LYS_390 & NZ & B_Glu_37 & OE1 & 6.249 \\
\hline $2 \mathrm{AJF}$ & F_LYS_390 & $\mathrm{NZ}$ & B_Glu_37 & OE2 & 8.015 \\
\hline $2 \mathrm{AJF}$ & F_LYS_390 & NZ & B_ASP_38 & OD1 & 11.056 \\
\hline $2 \mathrm{AJF}$ & F_Arg_426 & NH1 & B_ASP_355 & OD1 & 11.601 \\
\hline $2 \mathrm{AJF}$ & F_Arg_426 & NH1 & B_ASP_355 & OD2 & 10.740 \\
\hline $2 \mathrm{AJF}$ & F_Arg_426 & $\mathrm{NH} 2$ & B_ASP_355 & OD1 & 9.511 \\
\hline $2 \mathrm{AJF}$ & F_Arg_426 & $\mathrm{NH} 2$ & B_ASP_355 & OD2 & 8.774 \\
\hline $2 \mathrm{AJF}$ & F_HIS_445 & ND1 & B_Glu_23 & OE1 & 11.906 \\
\hline $2 \mathrm{AJF}$ & F_HIS_445 & ND1 & B_Glu_23 & OE2 & 11.869 \\
\hline $2 \mathrm{AJF}$ & F_LYS_447 & $\mathrm{NZ}$ & B_Glu_23 & OE1 & 10.486 \\
\hline $2 \mathrm{AJF}$ & F_LYS_447 & $\mathrm{NZ}$ & B_Glu_23 & OE2 & 10.922 \\
\hline $2 \mathrm{AJF}$ & F_LYS_447 & NZ & B_ASP_30 & OD2 & 11.643 \\
\hline
\end{tabular}

Table 9. A special 2AJF-specific structural scanning of salt bridging networks. In this table, the residue naming scheme is chain ID_residue name_residue number.

Overall, this article puts forward a comprehensive set of structural analysis of all SARS-CoV spike protein RBD domain-related structures, in the hope that it may be of certain use in our battle against coronaviruses such as SARS-CoV $[37,39,40]$ in future.

Author Contributions: Conceptualization, W.L.; methodology, W.L.; software, W.L.; validation, W.L.; formal analysis, W.L.; investigation, W.L.; resources, W.L.; data duration, W.L.; writing-original draft preparation, W.L.; writing-review and editing, W.L.; visualization, W.L.; supervision, W.L.; project administration, W.L.; funding acquisition, not applicable.

Funding: This research received no external funding.

Conflicts of Interest: The author declares no conflict of interest.

1. Chan, J.F.W.; Kok, K.H.; Zhu, Z.; Chu, H.; To, K.K.W.; Yuan, S.; Yuen, K.Y. Genomic characterization of the 2019 novel human-pathogenic coronavirus isolated from a patient with atypical pneumonia after visiting Wuhan. Emerging Microbes \& Infections 2020, 9, 221-236.

2. Chan, J.F.W.; Yuan, S.; Kok, K.H.; To, K.K.W.; Chu, H.; Yang, J.; Xing, F.; Liu, J.; Yip, C.C.Y.; Poon, R.W.S.; Tsoi, H.W.; Lo, S.K.F.; Chan, K.H.; Poon, V.K.M.; Chan, W.M.; Ip, J.D.; Cai, J.P.; Cheng, V.C.C.; Chen, H.; Hui, C.K.M.; Yuen, K.Y. A familial cluster of pneumonia associated with the 2019 novel coronavirus indicating person-to-person transmission: a study of a family cluster. The Lancet 2020, 395, 514-523. 
3. Chen, N.; Zhou, M.; Dong, X.; Qu, J.; Gong, F.; Han, Y.; Qiu, Y.; Wang, J.; Liu, Y.; Wei, Y.; Xia, J.; Yu, T.; Zhang, X.; Zhang, L. Epidemiological and clinical characteristics of 99 cases of 2019 novel coronavirus pneumonia in Wuhan, China: a descriptive study. The Lancet 2020, 395, 507-513.

4. Wu, F.; Zhao, S.; Yu, B.; Chen, Y.M.; Wang, W.; Song, Z.G.; Hu, Y.; Tao, Z.W.; Tian, J.H.; Pei, Y.Y.; Yuan, M.L.; Zhang, Y.L.; Dai, F.H.; Liu, Y.; Wang, Q.M.; Zheng, J.J.; Xu, L.; Holmes, E.C.; Zhang, Y.Z. A new coronavirus associated with human respiratory disease in China. Nature 2020.

5. Li, F. Structure of SARS Coronavirus Spike Receptor-Binding Domain Complexed with Receptor. Science 2005, 309, 1864-1868.

6. Wan, Y.; Shang, J.; Graham, R.; Baric, R.S.; Li, F. Receptor recognition by novel coronavirus from Wuhan: An analysis based on decade-long structural studies of SARS. Journal of Virology 2020.

7. Zakhartchouk, A.N.; Sharon, C.; Satkunarajah, M.; Auperin, T.; Viswanathan, S.; Mutwiri, G.; Petric, M.; See, R.H.; Brunham, R.C.; Finlay, B.B.; Cameron, C.; Kelvin, D.J.; Cochrane, A.; Rini, J.M.; Babiuk, L.A. Immunogenicity of a receptor-binding domain of SARS coronavirus spike protein in mice: Implications for a subunit vaccine. Vaccine 2007, 25, 136-143.

8. He, Y.; Li, J.; Li, W.; Lustigman, S.; Farzan, M.; Jiang, S. Cross-Neutralization of Human and Palm Civet Severe Acute Respiratory Syndrome Coronaviruses by Antibodies Targeting the Receptor-Binding Domain of Spike Protein. The Journal of Immunology 2006, 176, 6085-6092.

9. Du, L.; Zhao, G.; He, Y.; Guo, Y.; Zheng, B.J.; Jiang, S.; Zhou, Y. Receptor-binding domain of SARS-CoV spike protein induces long-term protective immunity in an animal model. Vaccine 2007, 25, 2832-2838.

10. Chen, W.H.; Du, L.; Chag, S.M.; Ma, C.; Tricoche, N.; Tao, X.; Seid, C.A.; Hudspeth, E.M.; Lustigman, S.; Tseng, C.T.K.; Bottazzi, M.E.; Hotez, P.J.; Zhan, B.; Jiang, S. Yeast-expressed recombinant protein of the receptor-binding domain in SARS-CoV spike protein with deglycosylated forms as a SARS vaccine candidate. Human Vaccines \& Immunotherapeutics 2013, 10, 648-658.

11. Li, W.; Moore, M.J.; Vasilieva, N.; Sui, J.; Wong, S.K.; Berne, M.A.; Somasundaran, M.; Sullivan, J.L.; Luzuriaga, K.; Greenough, T.C.; Choe, H.; Farzan, M. Angiotensin-converting enzyme 2 is a functional receptor for the SARS coronavirus. Nature 2003, 426, 450-454.

12. Jiang, S.; Lu, L.; Liu, Q.; Xu, W.; Du, L. Receptor-binding domains of spike proteins of emerging or re-emerging viruses as targets for development of antiviral vaccines. Emerging Microbes $\mathcal{E}$ Infections 2012, $1,1-8$.

13. Hoffmann, M.; Kleine-Weber, H.; Krüger, N.; Müller, M.; Drosten, C.; Pöhlmann, S. The novel coronavirus 2019 (2019-nCoV) uses the SARS-coronavirus receptor ACE2 and the cellular protease TMPRSS2 for entry into target cells 2020.

14. HO, T.; WU, S.; CHEN, J.; WEI, Y.; CHENG, S.; CHANG, Y.; LIU, H.; HSIANG, C. Design and biological activities of novel inhibitory peptides for SARS-CoV spike protein and angiotensin-converting enzyme 2 interaction. Antiviral Research 2006, 69, 70-76.

15. Lin, H.X.; Feng, Y.; Wong, G.; Wang, L.; Li, B.; Zhao, X.; Li, Y.; Smaill, F.; Zhang, C. Identification of residues in the receptor-binding domain (RBD) of the spike protein of human coronavirus NL63 that are critical for the RBD-ACE2 receptor interaction. Journal of General Virology 2008, 89, 1015-1024.

16. Chen, W.H.; Chag, S.M.; Poongavanam, M.V.; Biter, A.B.; Ewere, E.A.; Rezende, W.; Seid, C.A.; Hudspeth, E.M.; Pollet, J.; McAtee, C.P.; Strych, U.; Bottazzi, M.E.; Hotez, P.J. Optimization of the Production Process and Characterization of the Yeast-Expressed SARS-CoV Recombinant Receptor-Binding Domain (RBD219-N1), a SARS Vaccine Candidate. Journal of Pharmaceutical Sciences 2017, 106, 1961-1970.

17. Du, L.; Zhao, G.; Lin, Y.; Sui, H.; Chan, C.; Ma, S.; He, Y.; Jiang, S.; Wu, C.; Yuen, K.Y.; Jin, D.Y.; Zhou, Y.; Zheng, B.J. Intranasal Vaccination of Recombinant Adeno-Associated Virus Encoding Receptor-Binding Domain of Severe Acute Respiratory Syndrome Coronavirus (SARS-CoV) Spike Protein Induces Strong Mucosal Immune Responses and Provides Long-Term Protection against SARS-CoV Infection. The Journal of Immunology 2008, 180, 948-956.

18. Yuan, Y.; Cao, D.; Zhang, Y.; Ma, J.; Qi, J.; Wang, Q.; Lu, G.; Wu, Y.; Yan, J.; Shi, Y.; Zhang, X.; Gao, G.F. Cryo-EM structures of MERS-CoV and SARS-CoV spike glycoproteins reveal the dynamic receptor binding domains. Nature Communications 2017, 8.

19. Kirchdoerfer, R.N.; Cottrell, C.A.; Wang, N.; Pallesen, J.; Yassine, H.M.; Turner, H.L.; Corbett, K.S.; Graham, B.S.; McLellan, J.S.; Ward, A.B. Pre-fusion structure of a human coronavirus spike protein. Nature 2016, $531,118-121$. 
20. Song, W.; Gui, M.; Wang, X.; Xiang, Y. Cryo-EM structure of the SARS coronavirus spike glycoprotein in complex with its host cell receptor ACE2. PLOS Pathogens 2018, 14, e1007236.

21. He, Y.; Zhou, Y.; Siddiqui, P.; Jiang, S. Inactivated SARS-CoV vaccine elicits high titers of spike protein-specific antibodies that block receptor binding and virus entry. Biochemical and Biophysical Research Communications 2004, 325, 445-452.

22. He, Y.; Jiang, S. Vaccine Design for Severe Acute Respiratory Syndrome Coronavirus. Viral Immunology 2005, 18, 327-332.

23. Du, L.; Ma, C.; Jiang, S. Antibodies induced by receptor-binding domain in spike protein of SARS-CoV do not cross-neutralize the novel human coronavirus hCoV-EMC. Journal of Infection 2013, 67, 348-350.

24. Ge, X.Y.; Li, J.L.; Yang, X.L.; Chmura, A.A.; Zhu, G.; Epstein, J.H.; Mazet, J.K.; Hu, B.; Zhang, W.; Peng, C.; Zhang, Y.J.; Luo, C.M.; Tan, B.; Wang, N.; Zhu, Y.; Crameri, G.; Zhang, S.Y.; Wang, L.F.; Daszak, P.; Shi, Z.L. Isolation and characterization of a bat SARS-like coronavirus that uses the ACE2 receptor. Nature 2013, 503, 535-538.

25. Beniac, D.R.; deVarennes, S.L.; Andonov, A.; He, R.; Booth, T.F. Conformational Reorganization of the SARS Coronavirus Spike Following Receptor Binding: Implications for Membrane Fusion. PLoS ONE 2007, 2, e1082.

26. Wu, K.; Li, W.; Peng, G.; Li, F. Crystal structure of NL63 respiratory coronavirus receptor-binding domain complexed with its human receptor. Proceedings of the National Academy of Sciences 2009, 106, 19970-19974.

27. Pak, J.E.; Sharon, C.; Satkunarajah, M.; Auperin, T.C.; Cameron, C.M.; Kelvin, D.J.; Seetharaman, J.; Cochrane, A.; Plummer, F.A.; Berry, J.D.; Rini, J.M. Structural Insights into Immune Recognition of the Severe Acute Respiratory Syndrome Coronavirus S Protein Receptor Binding Domain. Journal of Molecular Biology 2009, 388, 815-823.

28. Berman, H.; Henrick, K.; Nakamura, H. Announcing the worldwide Protein Data Bank. Nature Structural E Molecular Biology 2003, 10, 980-980.

29. Li, W. How do SMA-linked mutations of SMN1 lead to structural/functional deficiency of the SMA protein? PLOS ONE 2017, 12, e0178519.

30. DeLano, W.L. Pymol: An open-source molecular graphics tool. CCP4 Newsletter On Protein Crystallography 2002, 40, 82-92.

31. ter Meulen, J.; van den Brink, E.N.; Poon, L.L.M.; Marissen, W.E.; Leung, C.S.W.; Cox, F.; Cheung, C.Y.; Bakker, A.Q.; Bogaards, J.A.; van Deventer, E.; Preiser, W.; Doerr, H.W.; Chow, V.T.; de Kruif, J.; Peiris, J.S.M.; Goudsmit, J. Human Monoclonal Antibody Combination against SARS Coronavirus: Synergy and Coverage of Escape Mutants. PLoS Medicine 2006, 3, e237.

32. Du, L.; Zhao, G.; Li, L.; He, Y.; Zhou, Y.; Zheng, B.J.; Jiang, S. Antigenicity and immunogenicity of SARS-CoV S protein receptor-binding domain stably expressed in $\mathrm{CHO}$ cells. Biochemical and Biophysical Research Communications 2009, 384, 486-490.

33. Elshabrawy, H.A.; Coughlin, M.M.; Baker, S.C.; Prabhakar, B.S. Human Monoclonal Antibodies against Highly Conserved HR1 and HR2 Domains of the SARS-CoV Spike Protein Are More Broadly Neutralizing. PLOS ONE 2012, 7, e50366.

34. Zeng, F.; Hon, C.C.; Yip, C.W.; Law, K.M.; Yeung, Y.S.; Chan, K.H.; Peiris, J.S.M.; Leung, F.C.C. Quantitative comparison of the efficiency of antibodies against S1 and S2 subunit of SARS coronavirus spike protein in virus neutralization and blocking of receptor binding: Implications for the functional roles of S2 subunit. FEBS Letters 2006, 580, 5612-5620.

35. Cao, Z.; Liu, L.; Du, L.; Zhang, C.; Jiang, S.; Li, T.; He, Y. Potent and persistent antibody responses against the receptor-binding domain of SARS-CoV spike protein in recovered patients. Virology Journal 2010, 7, 299.

36. Zhang, X.; Wang, J.; Wen, K.; Mou, Z.; Zou, L.; Che, X.; Ni, B.; Wu, Y. Antibody Binding Site Mapping of SARS-CoV Spike Protein Receptor-Binding Domain by a Combination of Yeast Surface Display and Phage Peptide Library Screening. Viral Immunology 2009, 22, 407-415.

37. Sui, J.; Deming, M.; Rockx, B.; Liddington, R.C.; Zhu, Q.K.; Baric, R.S.; Marasco, W.A. Effects of Human Anti-Spike Protein Receptor Binding Domain Antibodies on Severe Acute Respiratory Syndrome Coronavirus Neutralization Escape and Fitness. Journal of Virology 2014, 88, 13769-13780.

38. Li, W. Structural and Functional Consequences of the SMA-Linked Missense Mutations of the Survival Motor Neuron Protein: A Brief Update. In Novel Aspects on Motor Neuron Disease [Working Title]; IntechOpen, 2019. 
39. Struck, A.W.; Axmann, M.; Pfefferle, S.; Drosten, C.; Meyer, B. A hexapeptide of the receptor-binding domain of SARS corona virus spike protein blocks viral entry into host cells via the human receptor ACE2. Antiviral Research 2012, 94, 288-296.

40. Bian, C.; Zhang, X.; Cai, X.; Zhang, L.; Chen, Z.; Zha, Y.; Xu, Y.; Xu, K.; Lu, W.; Yan, L.; Yuan, J.; Feng, J.; Hao, P.; Wang, Q.; Zhao, G.; Liu, G.; Zhu, X.; Shen, H.; Zheng, B.; Shen, B.; Sun, B. Conserved amino acids W423 and N424 in receptor-binding domain of SARS-CoV are potential targets for therapeutic monoclonal antibody. Virology 2009, 383, 39-46. 